\title{
Derechas del siglo XXI: marco analítico para comprender su reconfiguración a partir del caso chileno
}

\author{
Stéphanie Alenda
}

\section{Resumen}

Para analizar la reconfiguración de la coalición opositora de centro-derecha en Chile desde las elecciones presidenciales y parlamentarias de 2013, proponemos articular dos acercamientos teórico-metodológicos habitualmente disociados en la literatura especializada: la sociología de las instituciones partidistas y la de las redes que irrigan los partidos. En la primera parte del artículo, revisamos los aportes y limitaciones de las dos principales corrientes teóricas en las que se inscriben los estudios sobre las derechas (los enfoques societal y organizacional). Construimos, luego, un marco explicativo que muestra la necesidad de tomar en cuenta las dinámicas intra, inter y extra partidistas para comprender el cambio institucional. Haciendo confluir la institución y las redes, se puede en efecto comprobar que la institucionalización partidista y la reestructuración de los sistemas de partidos se juegan también en una amplia gama de organizaciones que rodean los partidos e inciden en las conductas de sus actores. En Chile, las reglas de la competencia para el control del poder político se encuentran en etapa de redefinición, por lo que el estudio de los cambios en la coalición de centro-derecha cobra especial interés y relevancia. Sin embargo, nuestra propuesta analítica pretende ser generalizable a otros sistemas políticos y otras derechas latinoamericanas, más allá del caso chileno.

Palabras clave: derechas; Chile; redes partidarias; instituciones partidarias; cambio partidario.

\begin{abstract}
In order to analyze the reconfiguration of the Chilean center-right opposition since 2013 elections, we propose to articulate two theoretico-methodological approaches, usually disconnected in specialized literature: sociology of partisan institutions and sociology of
\end{abstract}

\section{Acerca de la autora}

Este artículo forma parte del proyecto Fondecyt 1151503.

Ph.D. en Sociología. Profesora asociada y directora de la Escuela de Sociología de la Universidad Andrés Bello, Santiago de Chile. Correo electrónico: salenda@unab.cl 
the networks that irrigate those parties. First of all, we examine the contributions and limitations of the two main theoretical perspectives for the studies of right-wing parties (societal and organizational). We then elaborate a theoretical framework taking into account intra, inter and extra party dynamics to understand institutional change. Making institution and networks converge allows to see that party institutionalization and the (re)structuring of party systems proceed as well from a wide range of organizations that surround political parties, having an incidence on their actors' behaviors. In Chile, the rules of competition for the control of political power are currently being redefined; therefore the study of the changes within the center-right opposition acquires special interest and relevance. However, our analytical proposal aims to be generalizable to other political systems and right-wing Latin American parties, beyond the Chilean case. Keywords: right-wing parties; partisan networks; partisan institutions; party change; Chile.

Artigo recebido em 10 de março de 20I5; aceito para publicação em 22 de julho de 2015.

\section{Introducción}

Para explicar a posteriori ciertos logros electorales o, al revés, como parte de la estrategia de renovación de organizaciones partidistas que sufrieron derrotas electorales, la tesis de la "modernización" de las derechas o de las izquierdas ha sido esgrimida en diferentes ocasiones y contextos nacionales, tanto por los analistas como por los propios actores políticos. En el caso de la derecha chilena, la elección de Sebastián Piñera en 2010 reabrió el debate en torno al advenimiento de una "nueva derecha" 1 , lo que dio principalmente cuenta de una lucha por el monopolio de la definición legítima de la identidad del sector de parte “...de fuerzas política -la Unión

1. Sebastián Piñera en entrevista al diario El País del 7 de noviembre de 2010, "Estamos construyendo una nueva derecha". En cuanto a los intentos de teorización, véanse en particular a José Miguel Izquierdo, en "Nueva Derecha”, Ponencia en el Congreso de la Asociación chilena de ciencia política, 12 de noviembre de 2010. Por su parte, Correa Sutil (2004) y otros historiadores fijan el fin de la derecha oligárquica en la década de 1960 con la creación del Partido Nacional el 11 de mayo de 1966, mientras que otros académicos, tales como los politólogos Morales y Bugueño (2001), asocian ésta con la emergencia de la UDI. 
Demócrata Independiente (UDI) y Renovación Nacional (RN) ${ }^{3}$-, y de grupos políticos al interior de ellas - en competencia. Una corriente "liberal" emergió en la Alianza, haciendo temer a los más conservadores un deslizamiento hacia el centro; aparecieron también nuevos referentes políticos (Amplitud, en enero de 2014, y Evolución Política -Evópoli-, actualmente en proceso de constitución como partido), nuevos think tanks y fundaciones, junto a una nueva generación de investigadores sensibilizados a los temas de participación ciudadana y derechos humanos. Este recambio generacional se observó además en la renovación de las directivas partidistas, tanto en la UDI como en RN.

Dado que estos cambios tendrán indudables repercusiones en la conformación de la actual coalición opositora y, más ampliamente, en el sistema de partidos chilenos, el tema adquiere una gran relevancia para comprender lo que está en juego en esta "reestructuración de la competencia por el control del poder ejecutivo" (Mair, 2007, 243).

Para explicar estas transformaciones recientes y, más generalmente, el cambio partidista, tanto la teoría producida por la ciencia política de corriente principal (Thelen, 2004; Pierson, 2004; Mahoney y Thelen, 2010 entre otros), como la mirada en términos de construcción social de las organizaciones partidistas (Offerlé, 1987) potenciada por la sociología política francesa, resultan útiles. Ello, con el fin de poder centrar el análisis en las dimensiones organizacionales e institucionales de estos cambios, sobre los cuales los estudios han sido escasos, preguntándonos además cómo otros cambios que intervienen fuera de la política, vale decir en entornos sociales específicos, inciden en los procesos de institucionalización y afectan la organización interna de los partidos. Esta hipótesis, que encuentra sus raíces en un enfoque societal sobre los partidos, no ha sido trabajada por la ciencia política de corriente principal, y tampoco articulada con un enfoque organizacional. Como veremos, ambas perspectivas han tenido además

2. Partido fundado como movimiento político en 1983. Su principal ideólogo fue el abogado, político y profesor universitario Jaime Guzmán, uno de los redactores de la Constitución Política de 1980 y senador desde 1990 hasta su asesinato en 1991.

3. Partido fundado en 1987 de cara al plebiscito de 1988 sobre la continuación del General Pinochet en el poder. RN nace de una alianza entre diferentes movimientos políticos de derecha y centro-derecha: principalmente el Movimiento de Unión Nacional (MUN), la Unión Demócrata Independiente (UDI), el Frente Nacional del Trabajo (FNT). 
dificultades tanto para dar cuenta de las especificidades de partidos de centro-derecha indudablemente muy diversos, como para explicar sus mutaciones organizacionales de largo y más corto plazo.

\section{Los enfoques teóricos sobre las derechas}

\section{El enfoque societal: aportes y limitaciones para explicar el cambio partidista}

Influenciado por la perspectiva marxista, según la cual los partidos son expresiones de las clases sociales, este enfoque vincula específicamente la derecha con la defensa de la posición de clase dominante y con la preservación del orden capitalista. Su formulación más notable se encuentra en la teoría sobre la formación de los sistemas de partidos en Europa de Lipset y Rokkan (1967), según la cual cada partido es la expresión de oposiciones sociales o culturales antiguas (centro/periferia, Estado/Iglesia, urbano/ rural), que preexisten a aquella formación. Conforme a este planteamiento, la derecha se estructura en base a un proceso histórico fundamental, la Revolución Industrial, que da lugar a partir de la segunda mitad del siglo XIX a una oposición entre los detentores del capital (la burguesía) y las fuerzas que representan el mundo del trabajo industrial (el proletariado obrero). En cuanto a sus diversas expresiones (partidos conservador, liberal, demócrata-cristiano etc.), dependen de la naturaleza de los clivajes sociales y culturales propios de la historia de las sociedades europeas. En otras palabras, se enmarcan en configuraciones nacionales diversas y específicas que contribuyen a explicar el peso relativo de las derechas, su fragmentación ideológica u organizacional o sus divisiones en función de líneas de fractura más o menos presentes en cada contexto.

Dada la estabilidad del sistema político chileno, este enfoque se impuso naturalmente en la ciencia política nacional ${ }^{4}$. Según Luna (2008), en términos ideológico-programáticos, el sistema de partidos chileno hasta 1973 se presentó "como excepcional en la región por su estructuración temprana, y de larga duración, en base a dos fisuras

4. Véanse: Dix (1989); Scully (1992); Scully y Valenzuela (1993); Valenzuela (1995, 1999); Tironi y Agüero (1999); Alcántara y Luna (2004); Luna (2008) entre otros. 
(clivajes) predominantes: el conflicto clerical-secular ${ }^{5}$ y el conflicto socioeconómico representado por el eje izquierda-derecha" (78). Sin embargo, además de no ser siempre explicativo de la estructuración de los sistemas de partidos ${ }^{6}$, su principal debilidad radica en no tomar en cuenta la evolución, tanto ideológica como organizacional, de los partidos, y en no permitir explicar sus transformaciones recientes. Al contrario, los partidos aparecen "congelados" a principios del siglo XX debido a la fuerza de los clivajes. Son asimismo a menudo reducidos a meras "expresiones" de estas líneas de fractura. En Chile, y al igual que en otros contextos, se comprobó así la persistencia del clivaje de clase (Altman, 2004), mientras otros politólogos resaltaron más bien la existencia de líneas divisorias superpuestas o en competencia (Alcántara y Luna, 2004; Fuentes, 2013; Elgueta y Herrera, 2013 entre otros), restando fuerza a la asociación inicial entre derecha y clase dominante.

Por último, el enfoque subestima el impacto de los factores institucionales y políticos en la generación de los sistemas de partidos, en particular uno de mucho interés para explicar el cambio partidista: el trabajo práctico y simbólico de los partidos o de agentes políticos que contribuye a mantener e incluso a producir los clivajes (Sartori, 1990; Offerlé, 1987). Es lo que refleja en Chile el debate en torno a la aparición de un nuevo clivaje autoritarismo/democracia, sin raíces socio-estructurales (ver entre otros a Tironi y Agüero, 1999; Valenzuela, 2001; Torcal y Mainwaring, 2003; Garretón, 2008).

Esta perspectiva societal estimula indagar en las dimensiones organizacionales e institucionales de las transformaciones partidistas en dos sentidos: 1) explorando la diversidad y modificaciones de los perfiles dirigenciales que contribuyen a la estructuración y reestructuración de los partidos, mediante encuestas socio-gráficas ${ }^{7} ; 2$ ) enfocando aquellas transforma-

5. El término clivaje también ha sido usado específicamente para describir la primera gran división de los partidos de derecha chilenos. Stuven (2000) centra este quiebre en las luchas liberales y conservadoras del siglo XIX.

6. Cabe por lo demás notar que si bien se ha demostrado que la tesis del congelamiento funciona en algunos contextos (por ejemplo en los casos escandinavo, británico o austriaco), ésta resulta poco explicativa en otros (español, francés etc.). Ver Alexandre-Collier y Jardin $(2004,51)$.

7. Cabe dar cuenta de la existencia en Chile de varios trabajos sobre la composición social de las élites políticas, entre otros Joignant y Navia (2003); Joignant (2007); Alenda y Sepúlveda (2009); Joignant y Güell (2011) y Cordero y Funk (2011). 
ciones como el resultado de los cambios que afectan las redes o entornos tradicionales de los partidos -principalmente empresariales y religiosos en el caso de las derechas -, considerando también el efecto de los think tanks en su producción y renovación ideológico-programática. Sin embargo, para contribuir a un marco analítico sobre el cambio partidista, estos dos aspectos deben ser complementados por los aportes del enfoque organizacional.

\section{El enfoque organizacional: aportes y limitaciones para explicar el cambio partidista}

Los acercamientos organizacionales constituyen otra gran corriente de análisis de los partidos políticos. Por lo general, se focalizan en las luchas de poder que se desarrollan al interior de los partidos y en los recursos asociados a éstas. Abarcan los procedimientos de selección y reclutamiento de dirigentes, la diversidad de carreras políticas (y profesionales) que confluyen en cada organización; o el estudio de la anatomía interna de los partidos (Sartori, 1976-1992, 99). A diferencia del enfoque societal, los partidos son clasificados en virtud de las formas de organización y de liderazgos que hacen su especificidad. Sus estrategias son más bien determinadas por variables políticas, tales como el mismo sistema de partidos (su número), el régimen político (parlamentario o presidencial) y las normas electorales, pero éstas son ante todo indisociables del marco de competencia interna propia de aquellas organizaciones.

A partir de la famosa distinción propuesta por Duverger (1951) entre partidos de cuadros y partidos de masas, la ciencia política se fue enriqueciendo de nuevas categorías que aparecieron a raíz de los cambios socio-políticos que afectaron las sociedades occidentales (Katz y Mair, 1995). Los partidos de derecha fueron inicialmente catalogados como partidos “de notables" (Weber, 1922-1995) o "de cuadros", estructurados de manera laxa y descentralizada, según el tipo ideal propuesto por Duverger, a diferencia de los partidos de masas o de "militantes" (Offerlé, 1987). Conforme esta tipología, mientras las actividades de reclutamiento y la formación política de la membresía resultaban fundamentales en la vida interna de los partidos de izquierda, los partidos de "notables" que contaban con 
un número de miembros selectos y reducidos, financistas de sus propias organizaciones, no veían la necesidad de ampliar su membresía. Ahora bien, lo que muestran los estudios más recientes es que no aparece un esquema organizacional que permita dar cuenta específicamente de estas formaciones políticas, primero debido a su heterogeneidad organizacional (desde los partidos demócrata-cristianos hasta la derecha radical en Europa); segundo, dada la tendencia a una atenuación de la distinción entre partidos de cuadros y partidos de masas.

En primer lugar, los partidos de derecha tendieron a mimetizarse con sus adversarios. En efecto, junto con la extensión del sufragio, el formato de partidos compuestos de redes de notables perdió su funcionalidad. Los partidos de derecha empezaron a implementar un sistema de cotizaciones y encuadramiento de sus militantes y buscaron implantarse a nivel local. Es así cómo el partido conservador británico, estudiado por McKenzie (1955), pasó de conformar un círculo parlamentario reducido a sumar tres millones de adherentes luego de la Segunda Guerra mundial. En segundo lugar, se produjo un declive del voto de clase, que coincide con la emergencia de los partidos catch-all (Kirchheimer, 1966) en un contexto de debilitamiento del clivaje izquierda-derecha. En tercer lugar, la merma global de los efectivos de afiliados contribuyó también a esta atenuación, pudiendo ser interpretada en el sentido de una vuelta al ethos burgués de los partidos de notables.

Vemos, por lo tanto, que estas tipologías no permiten dar cuenta de la especificidad organizacional de las derechas, a lo cual se suma que los estudios organizacionales no han sido muy capaces de interpretar los cambios incesantes que atraviesan aquellas organizaciones (Lagroye, 1989 citado por Sawicki, 2011). En efecto, los trabajos sobre el reclutamiento o la selección de candidatos, generalmente, no se interesan por las propiedades sociales del personal político estudiado, cuando conocer éstas constituye un desafío ineludible para investigar seriamente las transformaciones del reclutamiento político (Gaxie, 1980), la renovación de cuadros y dirigentes o la profesionalización política (Offerlé, 1999). De ahí la necesaria reconexión del enfoque organizacional con la perspectiva societal. Sin embargo, sostenemos que el enfoque organizacional debe además ser enriquecido por las perspectivas 
que abre la sociología de la institución (Lagroye y Offerlé, 2011), la cual propone articular en un mismo marco analítico las reglas y los jugadores, tradicionalmente disociados (North, 1990, 4-5). Se debe abordar comparativamente las derechas como productos de la dialéctica entre las prácticas individuales que hacen existir tipos particulares de "asociación" (Weber, 1922-1995) y las conductas autorizadas en ellas (Fretel, 2011, 195-6). Para que este abordaje permita llegar a un marco explicativo integral del cambio institucional con sus dinámicas intra, inter y extra partidistas, esta sociología comparativa de las instituciones partidistas debe a la vez articularse con una sociología comparativa de sus entornos o redes sociales.

\section{Explicar el cambio partidista en la confluencia de la instituci- ón y de las redes}

\section{Derechas y sociología de las instituciones partidistas}

La sociología de las instituciones partidistas ${ }^{8}$ permite pensar articuladamente las coacciones que pesan sobre los miembros de una institución y los recursos o "movidas" individuales que concurren a su reproducción o reinvención. Reconcilia asimismo dos grandes posturas teóricas y visiones del mundo social: por un lado, la de la sociología de las organizaciones que dirige el foco sobre el margen de maniobra de actores dotados de recursos y competencias diferenciados, pero con tácticas limitadas por las reglas de la institución en la cual se desenvuelven (Crozier y Friedberg, 1977); por otro, el análisis sea del "poder disciplinario" de la institución (Foucault, 1975), sea de su capacidad de modificar el sistema de esquemas incorporado duraderamente por los individuos ( habitus) mediante lo que Bourdieu llama un "acto de institución” (Bourdieu, 1982, 59). Adscribiéndonos a esta perspectiva, sostenemos que enfocar el partido político preferentemente como una institución ofrece un marco teórico y metodológico para pensar con mayor eficacia e integralidad el cambio organizacional.

8. En la compilación de Lagroye y Offerlé, Sociologie de l'institution (2011), remitimos en particular al capítulo de Julien Fretel sobre el centro francés, UDF, Modem. 
Este planteamiento converge con varios esfuerzos de corriente principal que buscan explicar el cambio partidista. Sobre el caso argentino, Levitsky (2003) mostró por ejemplo que la rápida adopción de reformas neoliberales por el partido justicialista durante la presidencia de Carlos Menem fue posible por tratarse de un partido "débilmente institucionalizado" y que los partidos fuertemente institucionalizados tienden a adaptarse al cambio de manera más gradual y lenta que las instituciones débiles (Levitsky y Murillo, 2010). Por su parte, la teoría del cambio incremental (Mahoney; Thelen, 2010) permite precisamente diferenciar aquellas variaciones a través de una tipología que hace derivar el cambio de la especificidad de las propiedades institucionales, asociadas a su vez a diferentes tipos de agentes de cambio, en el marco de contextos particulares (Mahoney y Thelen, 2010, 16-7). Esta teoría distingue asimismo diferentes formas en las que las instituciones pueden evolucionar, entre las cuales el injerto de nuevas reglas sobre las viejas ("superposición"), la atrofia gradual ("desvío"), la pérdida de relevancia ("desplazamiento") o los cambios en su función ("conversión”). Testeando este modelo de análisis en el caso de la UDI (Alenda, 2014b), pudimos comprobar que una alta rutina no constituye un impedimento para la adaptación de un partido político a cambios del entorno o a ciertos remezones internos y que, por ende, la institucionalización, así entendida, no reduciría a priori la capacidad adaptativa de las organizaciones, a diferencia de lo que planteó inicialmente Levitsky (2003) en su estudio del partido justicialista. Pretendemos seguir poniendo a prueba esta hipótesis en el caso de la UDI, "institución fuerte", sin embargo atravesada por tensiones internas que ya dificultaban la preservación de su homogeneidad antes del 2010 (Alenda, 2014a). La comparación con RN, partido "débilmente institucionalizado", ofrece la posibilidad de testear esta teoría del cambio en otro tipo de estructura organizacional.

El investigador debe por lo tanto interesarse en los aspectos de una institucionalización "informal”, que dependen de la capacidad de los partidos para inculcar a sus miembros esquemas de percepción, de pensamiento y de acción duraderos (los habitus, según Bourdieu), los mismos que regulan, aunque informalmente, el diario vivir partidista, plasmándose en reglas, roles diferenciados, vale decir en una "cultura institucional” específica, sistema de valores y de reglas cuya socio-génesis debe ser reconstruida (Alenda, 2014b). Esta preocupación por 
los procesos "informales" es coincidente con una parte de la agenda de investigación que Luna y Rovira (2011) sugieren abrir sobre las derechas de la región, ahondando mucho más en sus "características organizativas e institucionales". En sus palabras "el foco no debe estar puesto sólo en su institucionalidad formal, sino en sus mecánicas de funcionamiento cotidiano, abarcando múltiples arenas del quehacer partidista" (19). La revisión de literatura muestra que los estudios politológicos sobre las derechas en Chile se han dedicado más bien a estudiar la dinámica y las razones de su rendimiento electoral (Montes; Mainwaring y Ortega, 2000; Joignant y Navia, 2003; Morales y Bugueño, 2001; Berríos, 2007; Gamboa, 2007; Avendaño, 2009; Morales; Navia y Poveda, 2009; Luna, 2010; Luna y Rovira, 2011 entre otros). Fueron en efecto escasos los trabajos que pretendieron abordar el tema de su organización interna9 .

Nuestro marco analítico pretende de esta forma aportar a la comprensión del cambio institucional en diferentes tipos de partidos: los dos pilares de la derecha chilena desde la vuelta a la democracia (RN y la UDI), que cuentan con grados de institucionalización variables; y diferentes expresiones de esta nueva centro-derecha (Evópoli, Amplitud y Partido Regionalista Independiente -PRI- ${ }^{10}$ ) Para analizar dicho cambio, la variable "generación política", definida en relación a la antigüedad en la actividad político-partidista y entendida como "los recursos, formas de acción y percepción del mundo que traen los actores antes de ingresar al partido" (Vommaro, 2013, 25, sobre el $\mathrm{PRO}^{11}$ de Argentina) resulta clave. En el caso del PRO, que surge en un contexto de desestructuración del sistema partidista (Morresi y Vommaro, 2014), esta variable permitió aprehender la específica heterogeneidad de los dirigentes de derecha, que provienen sea de partidos en crisis, sea del mundo de las empresas, ONGs y think tanks. Asimismo, dicha variable permite enfocar los "conflictos generacionales" como el producto de socializaciones y representaciones

9. Sobre RN, véanse Barozet y Aubry (2005).

10. Partido creado en julio de 2006, que forma parte de la actual coalición de oposición, junto a la UDI, RN y Evópoli.

11. Propuesta Republicana (PRO) surgió en 2002 en torno al Mauricio Macri, empresario que hasta entonces no había tenido participación político-partidista y quien gobierna el distrito federal de Argentina desde 2007, situación inédita para una fuerza de centro-derecha en ese país. 
diferenciadas que conllevan diversas formas de pertenencia a la institución partidista, modificando inevitablemente la relación con ella ${ }^{12}$.

En cada caso, se tiene que explorar la relación dialéctica entre lo instituido y lo instituyente, devolviendo a la noción de institucionalización su dimensión histórica y procesual, y contribuyendo de esta forma a la reflexión crítica sobre la noción de institucionalización de los sistemas de partidos (Luna y Altman, 2011). Sostenemos en efecto que este proceso no puede ser comprendido sin tomar en cuenta las dinámicas societales que ocurren fuera de los partidos.

\section{Derechas y sociología de los entornos partidistas}

Proponemos analizar, articulado a lo anterior, las transformaciones de los partidos de derecha desde la sociedad en la que éstos se desenvuelven y los contextos históricos en los que evolucionan. Adoptando esta perspectiva, en un trabajo que hizo escuela sobre el partido comunista francés, Pudal (1989) mostró que las acciones de los dirigentes comunistas y sus creencias estaban muy lejos de obedecer únicamente a finalidades estratégicas impuestas por ciertas lógicas de competencia inherentes al partido y al "mercado" político (Gaxie, 2000). Comprobó en efecto que la génesis del partido comunista en Francia resultaba inseparable de diferentes fenómenos de corte socio-histórico, tales como las transformaciones de la clase obrera francesa del período de post-guerra o las trabas inherentes al sistema escolar que restringieron la promoción por la escuela de los "hijos del pueblo", fenómenos que fueron aprovechados por los dirigentes comunistas. Este análisis tomó así en cuenta las formas específicas de sociabilidad y de identidad local, sindical, u profesional. Por su lado, Sawicki optó por llamar "entorno partidista" al "conjunto de relaciones consolidadas entre grupos cuyos miembros no tienen necesariamente como finalidad principal participar en la construcción del partido político, aunque contribuyan a aquello mediante sus actividades" (Sawicki, 1997, 2011, 44). Esta noción nos parece fundamental para comprender cómo las propias transformaciones de esos entornos repercuten a su vez en las dinámicas del cambio partidista.

12. Sobre la UDI, véanse Alenda (2014a). 
En América Latina, las derechas poseen por lo general un vínculo privilegiado con los sectores empresariales (Luna; Rovira, 2011, 17), y algunos partidos mantienen además una relación fuerte con ciertas organizaciones religiosas, principalmente el Opus Dei y los Legionarios de Cristo en Chile. El papel de los think tanks y de los centros de estudio en general (Pinilla, 2012) forman también parte de aquellos entornos. "Vinculados directa o indirectamente al mundo político, a sectores empresariales o bien a una combinación de ambos" (Gárate Chateau, 2012, 475), concurren a la protección de los temas llamados "valóricos" o "morales" (derechos sexuales, interrupción del embarazo, eutanasia etc.). Mientras las organizaciones empresariales y religiosas contribuyen a la construcción partidista sin que aquello sea su finalidad primordial, y conocen también procesos propios de mutación; los think tanks de partidos políticos asumen, dentro de un mercado político competitivo, el desafío estratégico de producir ideas sobre políticas públicas, así como el de formar expertos para las tareas de gobierno. En ellos, se suelen también refugiar quienes han perdido las elecciones para preparar su regreso a la política.

Inspirándonos en la tipología de Sawicki (2011), nos parece fundamental prestar atención a dos tipos de redes: a) el conjunto de relaciones interpersonales entre los responsables de los diferentes componentes de una organización dada (cabe preguntarse específicamente cómo se constituyen los "círculos" internos ${ }^{13}$ de los partidos en torno a las mismas experiencias socializadoras) y b) el sistema de interdependencia entre organizaciones que intervienen en diferentes espacios cuyos actores son "multiposicionados" (Boltanski, 1973) o cuyos miembros comparten las mismas creencias o ideales. En Chile, el Informe de Desarrollo Humano del PNUD de 2004 ya revelaba una conexión entre los ámbitos económicos y políticos y los centros de investigación $(198)^{14}$; mostraba también la fuerte participación de la elite empresarial en movimientos religiosos (185), lo que fue investigado como una forma de distinción social y reproducción de las elites,

13. Véanse Degenne y Forsé (1994). Para el caso chileno, remitimos al trabajo de Espinoza (2010) sobre la conformación de las elites políticas, recurriendo al análisis de redes sociales.

14. Véanse también el trabajo exploratorio de Pina Stranger (2011) relativo a las interdependencias económicas y políticas de las elites chilenas en los últimos treinta años. 
que buscaban renovar su ethos frente a las orientaciones progresistas de la Iglesia (Thumala, 2011) y, más generalmente, de la sociedad. Cruzando perspectiva historiográfica y análisis de redes, se puede, por un lado, develar la estructura de relaciones estables e históricamente constituidas entre sectores sociales formalmente separados (político, económico, religioso) y, por otro, objetivar los contornos de estas redes mediante encuestas socio-gráficas y entrevistas en profundidad.

Asimismo, merecen ser exploradas las siguientes dimensiones de estas conexiones entre el campo político (think tanks incluidos) y las esferas económica y religiosa: i) el efecto sobre los cambios en los equilibrios internos de los partidos del ingreso de dirigentes que disponen de otras relaciones sociales construidas en los ámbitos privado y/o religioso; ii) las homologías de las coacciones ligadas a la cultura de los partidos y aquella propia de otras organizaciones, lo que Passeron $(1991,92)$ puso en evidencia en el caso de los partidos llamados "totalitarios", tales como el PC, frecuentemente comparado con la Iglesia católica; iii) el perfil y la multiposicionalidad de actores que participan en la producción, reproducción y transformación partidista, tanto organizacional como ideológica.

Precisamente en lo que se refiere al entorno empresarial, deben ser indagados los efectos de los cambios en las redes tradicionales de reclutamiento, apoyo e influencia, en particular en el caso de los partidos de derecha más consolidados (la UDI y RN), y puestas en evidencia la diversidad y transformación en el tiempo de los habitus empresariales que han alimentado de manera diferenciada ambos partidos. La vinculación de las elites empresariales con las elites intelectuales y políticas que han representado históricamente sus intereses, constituye en efecto un área de gran interés para poder observar la forma en que la demanda por una sociedad menos desigual está siendo procesada. Los think tanks más vinculados a los poderosos grupos económicos chilenos, sus dirigencias gremiales, así como los lobbistas mediante los cuales estas elites buscan influir en las decisiones gubernamentales o parlamentarias ${ }^{15}$, constituyen también un milieu preferencial para la observación de este fenómeno. En cuanto a las redes religiosas, en que recluta en particular la UDI (Insunza y Ortega, 2008), cabe preguntarse por los cambios

15. Sobre las estrategias no electorales para la acción política adoptadas por la derecha latinoamericana, véanse Luna y Rovira (2014). 
en esas instancias de socialización religiosa que pudieron afectar la capacidad de homogeneización moral de este partido.

Más allá del objeto de análisis constituido por la centro-derecha chilena, el marco analítico propuesto debería así permitir comprobar que las "estrategias" de los actores resultan tanto de sus posiciones en el entorno partidista y de los intereses o recursos ligados a éstas, como de los cálculos indisociables del marco de competencia propia de la institución partidista; también que la competencia política, la institucionalización partidista y la estructuración de los sistemas de partidos se juegan en una amplia gama de organizaciones que irrigan los partidos. Estar atentos a las transformaciones de estas redes es precisamente estar en condiciones de identificar cómo los cambios que intervienen desde fuera de la política afectan también la organización interna de los partidos. Por último, este modelo de análisis producido a partir del caso chileno puede ser útil para comprender más integralmente las recomposiciones de otras agrupaciones de centro-derecha en la región.

Figura I - Síntesis de nuestra propuesta analítica

Marco explicativo del cambio institucional en las derechas (CID)

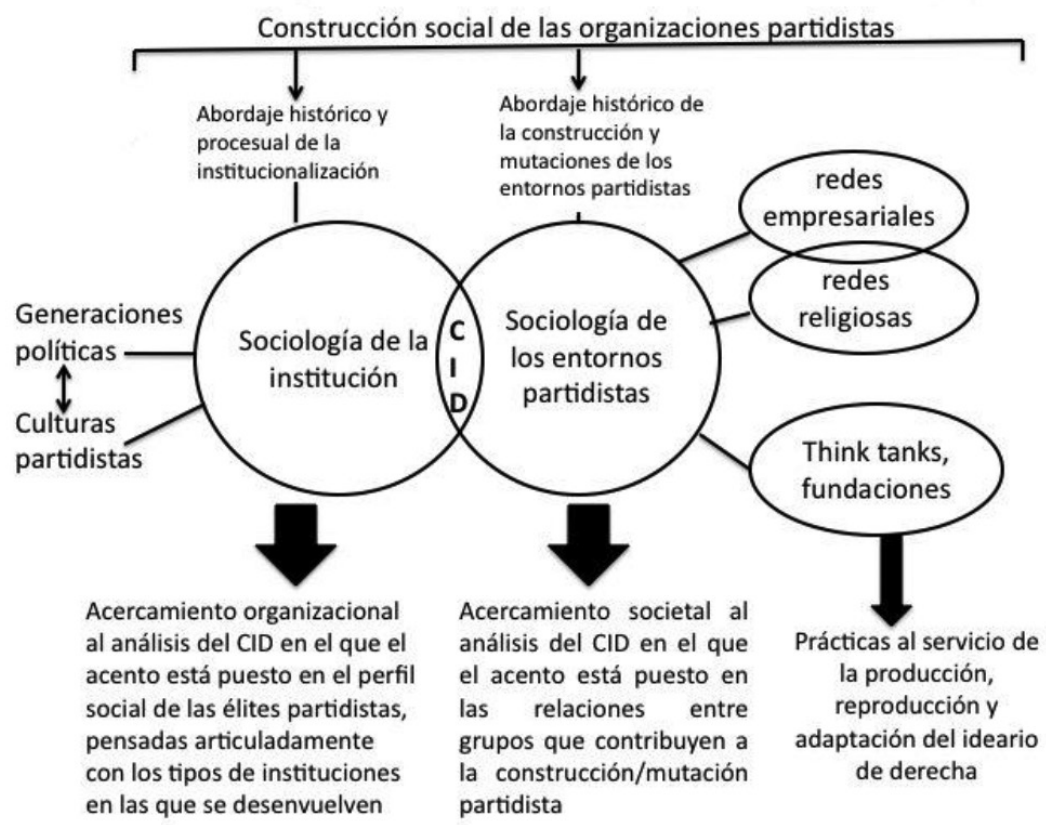




\section{Referencias}

ALCÁNTARA, M.; LUNA, J. P. (2004). Ideología y competencia partidista en dos post-transiciones: Chile y Uruguay en perspectiva comparada. Revista de Ciencia Política, vol. 24, n. 1, p. 128-168.

ALENDA, S.; SEPÚLVEDA, J. I. (2009). Pensar el cambio en las organizaciones partidistas: perfiles dirigenciales y trayectorias de moderación en la Concertación y la Alianza. En: Economía, instituciones y políticas en Chile. Serie Estudios, vol. IV. División de Estudios del Ministerio Secretaría General de la Presidencia, p. 135-180.

ALENDA, S. (2014a). Les avatars de la 'nouvelle droite' chilienne: la fabrique d'une institution partisane (1967-2010). Politix - Revue des sciences sociales du politique, vol. 106, n. 27, p. 135-161.

- (2014b). Cambio e institucionalización de la 'nueva derecha' chilena (19672010). Revista de Sociologia e Política, vol. 22, n. 52, p. 159-180.

ALEXANDRE-COLLIER, A.; JARDIN, X. (2004). Anatomie des droites européennes. París: Armand Colin.

ALTMAN, D. (2004). Redibujando el mapa electoral chileno: incidencia de factores socioeconómicos y género en las urnas. Revista de Ciencia Política, vol. 24, n. 2, p. 49-66.

AVENDAÑO, O. (2009). La oposición de derecha en Chile. El caso de la UDI en perspectiva comparada. Ponencia presentada al XXI Congreso Mundial de Ciencia Política. Santiago de Chile, 12-16 de julio.

BAROZET, E.; AUBRY, M. (2005). De las reformas internas a la candidatura presidencial autónoma: los nuevos caminos institucionales de Renovación Nacional. Politica, n. 45, p. 165-196.

BERRÍOS, F. (2007). La Unión Demócrata Independiente. En: HUNEEUS, F.; BERRÍOS, Y.; GAMBOA, R. (eds.). Las elecciones chilenas de 2005. Partidos, coaliciones y votantes en transición. Santiago: Catalonia, p. 29-52.

BOLTANSKI, L. (1973). L'espace positionnel: multiplicité des positions institutionnelles et habitus de classe. Revue française de sociologie, vol. 14, n. 1, p. 3-26.

BOURDIEU, P. (1982). Les rites comme actes d'institution. Actes de la recherche en sciences sociales, n. 43, p. 58-63.

CORDERO, R.; FUNK, R. (2011). La política como profesión. Cambio partidista y transformación social de la élite política en Chile, 1961-2006. Revista Política y Gobierno, vol. 18, n. 1, p. 39-71.

CORREA, S. (2004). Con las riendas del poder. La derecha chilena en el siglo XX. Santiago, Chile: Sudamericana.

CROZIER, M.; FRIEDBERG, E. (1977). L'acteur et le système. Les contraintes de l'action collective. París: Editions du Seuil. 
DEGENNE, A.; FORSE, M. (1994). Les réseaux sociaux. Une approche structurale en sociologie. París: Armand Colin.

DIX, R. (1989). Cleavage structures and party systems in Latin America. Comparative Politics, vol. 22, n. 1, p. 23-37.

DUVERGER, M. (1951). Les partis politiques. París: Armand Colin.

ELGUETA, R.; HERRERA, M. S. (2013). Dimensiones de competencia en la política chilena de los noventa: evaluación del impacto de un gobierno militar en la reestructuración del sistema de partidos. Revista del CLAD Reforma y Democracia, n. 56, p. 177-210.

ESPINOZA, V. (2010). Redes de poder y sociabilidad en la élite política chilena. Los parlamentarios 1990-2005. Revista Polis, vol. 9, n. 26, p. 251-86.

FRETEL, J. (2011). Habiter l'institution. Habitus, apprentissages et langages dans les institutions partisanes. En: LAGROYE, J.; OFFERLE, M. Sociologie de l'institution. París: Belin, p. 195-217.

FOUCAULT, M. (1975). Surveiller et punir. París: Gallimard.

FUENTES, C. (2013). El fraude: crónica sobre el plebiscito de la constitución de 1980. Santiago de Chile: Hueders.

GÁRATE, M. (2012). La revolución capitalista de Chile: (1973-2003). Santiago: Ediciones Universidad Alberto Hurtado.

GARRETÓN, M. A. (2008). Política, cultura y sociedad en el Bicentenario. Ponencia. Consejo Nacional de la Cultura, Santiago de Chile.

GAXIE, D. (1980). Les logiques du recrutement politique. Revue Française de Science Politique, vol. 30, n. 1, p. 5-45. . (2000). La Démocratie représentative. París: Montchrestien.

GAMBOA, R. (2007). Renovación nacional. Las elecciones presidenciales y parlamentarias chilenas de 2005. Santiago de Chile: Catalonia, p. 53-78.

INSUNZA, A.; ORTEGA, J. (2008). Legionarios de Cristo en Chile. Dios, dinero y poder. Santiago de Chile: UDP.

JOIGNANT, A. (2007). Modelos, juegos y artefactos. Supuestos, premisas e ilusiones de los estudios electorales y de sistemas de partidos en Chile (1988-2005). Estudios Públicos, n. 106, p. 205-71.

JOIGNANT, A.; GÜELL, P. (eds.). (2011). Notables, tecnócratas y mandarines. Santiago: UDP.

JOIGNANT, A.; NAVIA, P. (2003). De la política de individuos a los hombres del partido. Socialización, competencia política y penetración electoral de la UDI (1989-2001). Estudios Públicos, n. 89, p. 130-71.

KATZ, R.; MAIR, P. (1995). Changing models of party organization and party democracy: the emergence of the cartel party. Party Politics, vol. 1, n. 1, p. 5-28. 
KIRCHHEIMER, O. (1966). The transformation of the Western European party systems. En: LaPALOMBARA, J.; WINER, M. (eds.). Political parties and political development. Princeton: Princeton University, p. 177-200.

LAGROYE, J. (1989). Change and permanence in political parties. Political Studies, vol. 37, n. 3, p. 362-75.

LAGROYE, J.; OFFERLE, M. (2011). Sociologie de l'institution. París: Belin.

LEVISTKY, S. (2003). Transforming labor-based parties in Latin America. Argentine peronism in comparative perspective. Cambridge: Cambridge University.

LEVISTKY, S.; MURILLO, M. V. (2010). Variación en la fortaleza institucional. Revista de Sociología, n. 24, p. 31-56.

LIPSET, S.; ROKKAN, S. (1967). Party systems and voter alignments: cross-national perspectives. Nueva York: Free Press.

LUNA, J. P. (2010). Segmented party-voter linkages in Latin America: the case of the UDI. Journal of Latin American Studies, n. 42, p. 325-56.

LUNA, J. P.; ALTMAN, D. (2011). Uprooted but stable: chilean parties and the concept of party system institutionalization. Latin American Politics and Society, vol. 53, n. 2, p. 1-28.

LUNA, J. P.; ROVIRA, C. (2011). Las derechas gobernantes en América Latina: hacia una caracterización preliminar. Trabajo presentado en LASA Forum Summer 2011, vol. XLII, n. 3.

. (2014). The resilience of the Latin American right. Baltimore: Johns Hopkins University.

MAHONEY, J.; THELEN, K. (2010). Explaining institutional change: ambiguity, agency, and power. New York: Cambridge University.

MAINWARING, S.; TORCAL, M. (2003). Party system institutionalization and party system theory after the third wave of democratization. Notre Dame: The Helen Kellogg Institute for International Studies.

MAIR, P. (2007). Le changement des systèmes de partis. Revue internationale de politique comparée, vol. 14, n. 2, p. 243-61.

MCKENZIE, R. (1955). British political parties. The distribution of power with the conservative and labour parties. London: Heinemann.

MONTES, E.; MAINWARING, S.; ORTEGA, E. (2000). Rethinking the chilean party system. Journal of Latin American Studies, vol. 32, n. 3, p. 795-824.

MORALES, M.; BUGUEÑO, R. (2001). La UDI como expresión de la nueva derecha en Chile. Revista de Estudios Sociales, n. 107, p. 215-48.

MORALES, M.; NAVIA, P.; POVEDA, A. (2009). ¿Quién vota Piñera? Los determinantes de adhesión al candidato presidencial de la Alianza. En: UDP (informe anual) Cuarta encuesta nacional de Opinión pública UDP, Chile 2008: percepciones y actitudes sociales. ICSO-UDP, p. 48-56. 
MORRESI, S.; VOMMARO, G. (2014). Argentina: The Difficulties of the Partisan Right and the Case of Propuesta Republicana. En: LUNA, J.P.; ROVIRA KALTWASSER, C. (eds.). The Resilience of the Latin American Right. Baltimore: Johns Hopkins University Press, p. 319-345.

NORTH, D. C. (1990). Institutions, institutional change, and economic performance. New York: Cambridge University.

OFFERLÉ, M. (1987-2004). Les partis politiques. Paris: PUF. . (1999). Professions et profession politique. En: OFFERLÉ, M. La profession politique: XIX-XXème siècle. París: Belin, p. 7-35.

PASSERON, J.-C. (1991). Le Raisonnement sociologique. París: Nathan.

PIERSON, P. (2004). Politics in time: history, institutions, and social analysis. Princeton: Princeton University.

PINA STRANGER, A. (2011). Métodos de análisis de redes y elite económica. Serie Working papers ICSO-UDP, n. 1.

PINILLA, J. P. (2012). Think Tanks, saber experto y formación de agenda política en Chile actual. Revista Polis, vol. 11, n. 32, p. 119-40.

PNUD-Informe de Desarrollo Humano en Chile. (2004). El Poder, ¿̨para qué y para quién? Santiago de Chile.

PUDAL, B. (1989). Prendre Parti. Pour une sociologie historiqe du PCF. París: Presses de la FNSP.

SARTORI, G. (1976-1992). Partidos y sistemas de partidos. Madrid: Alianza.

SARTORI, G. (1990). The Sociology of Parties: A Critical Review. En: MAIR, P. (ed.). The West European Party System. Oxford: Oxford University Press, p. 150-182.

SAWICKI, F. (1997). Les réseaux du parti socialiste. Sociologie d'un milieu partisan. París: Belin.

. (2011). Para una sociología de los entornos y de las redes partidistas. Revista de Sociología, n. 25, p. 37-53.

SCULLY, T. (1992). Los partidos de centro y la evolución politica chilena. Santiago. Chile: CIEPLAN-Notre Dame.

SCULLY, T.; VALENZUELA, S. (1993). De la democracia a la democracia. Continuidad y variaciones en las preferencias del electorado y en el sistema de partidos en Chile. Estudios Públicos, n. 51, p. 195-228.

STUVEN, A. M. (2000). La seducción de un orden. Las élites y la construcción de Chile en las polémicas culturales y políticas del siglo XIX. Santiago de Chile: Ediciones Universidad Católica de Chile.

THELEN, K. (2004). How Institutions evolve. The political economy of skills in Germany, Britain, the United States, and Japan. Cambridge: Cambridge University. TIRONI, E.; AGÜERO, F. (1999). ¿Sobrevivirá el nuevo paisaje político chileno? Estudios Públicos, n. 74, p. 151-68. 
TORCAL, M.; MAINWARING, S. (2003). The political re-crafting of social bases of party competition: the case of Chile 1973-1995. British Journal of Political Science, n. 33, p. 55-84.

THUMALA, M. A. (2011). Distinción de base religiosa en la elite económica chilena: algunas limitaciones en el enfoque de Bourdieu. En: JOIGNANT, A.; GÜELL, P. (eds.). Notables, tecnócratas y mandarines. Santiago: UDP, p. 185-202.

VALENZUELA, A. (2001). Crisis de representación y reforma politica en Chile. Trabajo presentado en el marco del proyecto para la reforma de los partidos en Chile patrocinado por el Centro de Estudios Públicos (CEP) y la Corporación de Estudios para Latinoamérica (CIEPLAN), Santiago de Chile.

VALENZUELA, S. (1995). Orígenes y transformaciones del sistema de partidos en Chile. Estudios Públicos, n. 58, p. 6-77. . (1999). Respuesta a Eugenio Tironi y Felipe Agüero. Reflexiones sobre el presente y futuro del paisaje político chileno a la luz de su pasado. Estudios Públicos, n. 75, p. 273-90.

VOMMARO, G. (2013). El estudio del reclutamiento de los dirigentes de una organización politica a través de sus generaciones políticas: el caso del PRO en la ciudad de Buenos Aires. En: CONGRESO LASA, Washington. . (2014). Argentina. The difficulties of the partisan right and the case of propuesta republicana. En: LUNA, J. P.; ROVIRA, C. (eds.). The resilience of the Latin American right. Baltimore: Johns Hopkins University.

WEBER, M. (1922-1995). Economie et société. Tome 1. París: Plon. 